\title{
Manejo da adubação nitrogenada nas culturas de alface, repolho e salsa
}

\section{Mariana Vieira Nascimento ${ }^{1}$, Rogério Lamim Silva Junior ${ }^{1}$, Luiz Roberto Fernandes ${ }^{1}$, Ricardo Caldas Xavier ${ }^{1}$, Katiane Santiago Silva Benett ${ }^{1}$, Alexsander Seleguini ${ }^{2}$, Cleiton Gredson Sabin Benett ${ }^{3}$}

\author{
${ }^{1}$ Universidade Estadual de Goiás, Campus Ipameri, Ipameri, Goiás, Brasil. E-mail: nascimento_mariana1@ @otmail.com, \\ rogeriolamimj@gmail.com, pezao_08@hotmail.com, ricardouna@hotmail.com, katiane.benett@gmail.com \\ ${ }^{2}$ Universidade Federal de Goiàs, Goiânia, Goiás, Brasil. E-mail: aseleguini@ gmail.com \\ ${ }^{3}$ Instituto Federal Goiano, Campus de Urutaí, Urutaí, Goiás, Brasil. E-mail: cleiton.benett@ifgoiano.edu.br
}

Recebido: 04/04/2016; Aceito: 26/02/2017

\section{RESUMO}

$\mathrm{O}$ adequado fornecimento de nitrogênio é um dos principais fatores de manejo que afetam o rendimento e a qualidade da produção de hortaliças. Este trabalho teve como objetivo avaliar os efeitos da aplicação de doses e fontes de nitrogênio no desenvolvimento e produtividade de alface, repolho e salsa. Os experimentos foram desenvolvidos na Universidade Estadual de Goiás, Campus Ipameri no período de agosto a novembro de 2014. O delineamento experimental utilizado para cada espécie, foi o de blocos ao acaso, em esquema fatorial $2 \times 5$, sendo duas fontes de $\mathrm{N}$ (ureia convencional e ureia revestida com polímero) e cinco doses de nitrogênio (de acordo exigência de cada espécie), com quatro repetições. As espécies utilizadas foram alface crespa Itapuã Super, repolho chato de quintal e salsa graúda portuguesa. As doses de $\mathrm{N}$ foram parceladas em três aplicações iguais, em cobertura, sendo que para a cultura da alface foram aplicados 0, 60, 120, 180 e $240 \mathrm{~kg}$ ha-1 de N; para o repolho $0,75,150,225$ e $300 \mathrm{~kg}$ ha- 1 de $\mathrm{N}$ e para a salsa $0,40,80,120$ e $160 \mathrm{~kg}$ ha- $1 \mathrm{de} \mathrm{N}$. As fontes e doses de nitrogênio não influenciaram nas características produtivas da cultura da alface, repolho e salva.

Palavras-chave: Lactuca sativa, Brassica oleracea var. capitata, Petroselinum crispum, fontes de nitrogênio.

\section{Nitrogen fertilization management for lettuce, cabbage and parsley crops}

\begin{abstract}
The adequate supply of nitrogen is one of the key management factors that affect the yield and quality of vegetables produced. This study aimed to evaluate the effects of nitrogen application rates and sources on the development and productivity of lettuce, cabbage and parsley. The experiments were conducted at the State University of Goiás, Campus Ipameri in the period from August to November 2014. The experimental design for each species was the randomized blocks in factorial $2 \times 5$, two $\mathrm{N}$ sources (conventional urea and coated urea polymer) and five doses of nitrogen (according requirement of each species) with four replications. The species used were crinkly lettuce Itapuã Super cabbage Chato de Quintal and salsa Portuguese big shots. N doses were divided in three equal applications, cover, and for the lettuce were applied $0,60,120,180$ and $240 \mathrm{~kg} \mathrm{ha}^{-1} \mathrm{~N}$; for cabbage $0,75,150,225$ and $300 \mathrm{~kg} \mathrm{ha}^{-1} \mathrm{~N}$ and parsley $0,40,80,120$ and $160 \mathrm{~kg} \mathrm{ha}^{-1} \mathrm{~N}$. Nitrogen rates do not influence the productive characteristics of lettuce, cabbage and saved.
\end{abstract}

Key words: Lactuca sativa, Brassica oleracea var. capitata, Petroselinum crispum, nitrogen sources. 


\section{Introdução}

As hortaliças folhosas são espécies hortícolas quem vem ganhando destaque pela grande procura como opção nas refeições. Estas hortaliças se enquadram como as mais consumidas no mundo apresentando grande diversidade de cor, textura, sabor, forma de preparo e uso; dentre as quais se destacam as culturas da alface, do repolho e da salsa. Para suprir a demanda do mercado consumidor em quantidade, qualidade $\mathrm{e}$ regularidade de hortaliças, torna-se necessário o uso de sistemas de cultivo com alta produtividade.

A produção de diferentes espécies de hortaliças normalmente se dá sob condições de cultivo intensivo, havendo a necessidade de adequado suprimento de nutrientes desde o estádio de plântula até a colheita, haja visto que o desequilíbrio nutricional, seja por carência ou excesso de nutrientes, é fator estressante para a planta (FURLANI; PURQUERIO, 2010).

$\mathrm{O}$ nitrogênio $(\mathrm{N})$ é um dos nutrientes que mais contribuem para o metabolismo fisiológico das plantas e está relacionado diretamente na formação de proteínas. Algumas espécies, em particular, apresentam alta exigência de disponibilidade de $\mathrm{N}$. Tal fato é uma das condições responsáveis pela utilização de altas doses de fertilizantes nitrogenados ao longo do ciclo de cultivo das hortaliças folhosas (ZAGO et al., 2008). De acordo Filgueira (2012), o N é o segundo nutriente mais exigido pelas hortaliças. Nas hortaliças folhosas, o efeito deste nutriente promove aumento na produtividade; o fornecimento de doses adequadas estimula o crescimento vegetativo, expande a área fotossinteticamente ativa, além de proporcionar folhas com coloração mais atrativa e suculentas.

$\mathrm{O} \mathrm{N}$ tem papel fundamental na produção, contudo, seus efeitos variam com as condições ambientais de cada região e com o estádio de desenvolvimento da planta (CARVALHO; NAKAGAWA, 2000). O N também está presente em vários compostos nas plantas, sendo os principais: aminoácidos, ácidos nucléicos e clorofila (EPSTEIN; BLOOM, 2005).

De acordo com Lezana Júnior e Carrasco (2002), o $\mathrm{N}$ é um elemento que é facilmente perdido por lixiviação, volatilização, denitrificação no sistema soloplanta-atmosfera. Uma das alternativas para aumentar a sua absorção pelas plantas é parcelar a dose recomendada em várias aplicações e/ou utilizar fontes de $\mathrm{N}$ que apresentem liberação lenta ou controlada do nutriente. De acordo com Caetano et al. (2015), os estudos com utilização de ureia de liberação lenta e/ou revestidas com polímeros são incipientes, o que justifica o uso destes fertilizantes visando reduzir as perdas de $\mathrm{N}$.

A adubação nitrogenada deve ser balanceada em hortaliças folhosas; para a alface a dose adequada de $\mathrm{N}$ a ser aplicada é de suma importância, tanto para a produção da cultura e sua qualidade como para a saúde humana e o meio ambiente. Em geral, a adubação nitrogenada recomendada para a alface está em torno de $100 \mathrm{~kg} \mathrm{ha}^{-1}$ parcelados, conforme Ribeiro et al. (1999). Pereira et al. (2003) verificaram que a adubação nitrogenada entre 75 a $300 \mathrm{mg} \mathrm{dm}^{-3}$ resultou em acréscimo na produção da alface cv. "Verônica".

Outras hortaliças folhosas responsivas à adubação nitrogenada são as Brássicas, dentre elas, o repolho. A fertilização com $\mathrm{N}$ aumenta a produção (AQUINO et al., 2005; DIN et al., 2007) e otimiza a qualidade do repolho (HAQUE et al., 2006). Assim, é necessário aplicar fertilizante nitrogenado, em dose adequada, para a obtenção de plantas com cabeças compactas (firmeza), qualidade desejada pelo consumidor, conforme Moreira e Vidigal (2011).

Dentre as plantas utilizadas como condimento, a salsa pode facilmente ser encontrada em hortas domésticas. Assim, a produção em grande quantidade fica inviável devido à baixa procura por essa folhosa. Nesse contexto, a aplicação nitrogenada pode melhorar a produção, proporcionando folhas mais vigorosas. Conforme Filgueira (2012), a aplicação de N na salsa varia de 20 a $30 \mathrm{~kg} \mathrm{ha}^{-1}$ por parcelamento.

Diante do exposto, o objetivo do presente trabalho foi de investigar o efeito da aplicação de diferentes doses e fontes de adubação nitrogenada no desenvolvimento e na produtividade de alface, repolho e salsa.

\section{Material e Métodos}

Neste estudo foram conduzidos três experimentos na área experimental da Universidade Estadual de Goiás, campus de Ipameri-GO $\left(17^{\circ} 43^{\prime}\right.$ de latitude sul e $48^{\circ} 22^{\prime}$ de longitude oeste e altitude média de $800 \mathrm{~m}$ ) no período de agosto a novembro de 2014. O clima da região, segundo a classificação de Köppen, é definindo como Tropical Úmido (AW), com temperaturas elevadas e chuvas no verão e seca no inverno. O solo da área experimental foi classificado como Latossolo Vermelho-Amarelo Distrófico (SANTOS et al., 2013), de textura média (390 $\mathrm{g} \mathrm{kg}^{-1}$ de argila, $97 \mathrm{~g} \mathrm{~kg}^{-1}$ de silte e $513 \mathrm{~g} \mathrm{~kg}^{-1}$ de areia).

As propriedades químicas do solo foram determinadas antes da instalação do experimento, segundo metodologia proposta por Ribeiro et al. (1999), apresentando os seguintes valores para a camada de 0,0 0,20 m: $19 \mathrm{mg} \mathrm{dm}^{-3}$ de P (Mehlich-1); $30 \mathrm{~g} \mathrm{dm}^{-3} \mathrm{de}$ matéria orgânica; $\mathrm{pH}$ em $\mathrm{CaCl}_{2}$ de 5,3;3,9;35,0;11,0 e 28,0 $\mathrm{mmol}_{\mathrm{c}} \mathrm{dm}^{-3}$ de $\mathrm{K}, \mathrm{Ca}, \mathrm{Mg}$ e $\mathrm{H}+\mathrm{Al}$, respectivamente; saturação por bases de $64 \%$.

Foi avaliado o efeito da adubação nitrogenada no desenvolvimento das seguintes hortaliças folhosas: alface crespa Itapuã Super (Lactuca sativa), repolho 
híbrido Astrus Plus (Brassica oleracea var. capitata) e salsa Graúda Portuguesa (Petroselinum crispum).

O delineamento experimental utilizado para cada espécie estudada foi o de blocos ao acaso, em esquema fatorial $2 \times 5$, sendo constituído da aplicação de duas fontes de $\mathrm{N}$ (ureia convencional e ureia revestida com polímero) e cinco doses de adubação nitrogenada, com quatro repetições. As quantidades de $\mathrm{N}$ aplicadas foram baseadas na exigência de cada espécie: sendo aplicado na cultura da alface $0,60,120,180$ e $240 \mathrm{~kg} \mathrm{ha}^{-1}$ de $\mathrm{N}$ aos 15, 30 e 45 DAT (dias após o transplante).

Para a cultura do repolho foram utilizados 0,75 , 150, 225 e $300 \mathrm{~kg} \mathrm{ha}^{-1}$ de $\mathrm{N}$ aos 20, 40 e 60 DAT. Para a cultura da salsa aplicou-se $0,40,80,120$ e $160 \mathrm{~kg} \mathrm{ha}^{-1}$ de $\mathrm{N}$ aos 20, 30 e 40 DAE (dias após a emergência).

Foram preparados quatro canteiros com $1,0 \mathrm{~m}$ de largura, 0,2 $\mathrm{m}$ de altura e comprimento variável em função dos espaçamentos utilizados para cada espécie. A adubação básica foi realizada no momento do plantio onde se utilizou 20, 180 e $80 \mathrm{~kg} \mathrm{ha}^{-1}$ de $\mathrm{N}, \mathrm{P}_{2} \mathrm{O}_{5}$ e $\mathrm{K}_{2} \mathrm{O}$, respectivamente. Para as culturas da alface e do repolho as mudas foram produzidas em bandejas de poliestireno expandido com 128 células, utilizando-se duas sementes por célula. Posteriormente, realizou-se o desbaste deixando apenas uma plântula por célula.

O transplante foi realizado para o local definitivo quando as mudas apresentavam em torno de cinco folhas definitivas, no espaçamento de $0,8 \times 0,4 \mathrm{~m}$ e de $0,3 \times 0,25 \mathrm{~m}$ para a cultura do repolho e da alface, respectivamente. Cada parcela experimental foi constituída de quatro fileiras com quatro plantas cada, sendo considerada como área útil as quatro plantas das duas fileiras centrais.

Para a cultura da salsa a semeadura foi realizada diretamente nos canteiros com espaçamento de $0,25 \mathrm{x}$ 0,10 m, sendo as parcelas experimentais constituídas de quatro linhas espaçadas e comprimento de 1,0 m. A área útil considerada foram as duas linhas centrais de cada parcela.

Para a adubação nitrogenada foram utilizadas como fonte de $\mathrm{N}$ a ureia convencional e a ureia revestida, sendo os tratamentos aplicados em cobertura e parcelados conforme da espécie. O controle de plantas invasoras foi realizado através de capinas manual, e os demais tratos culturais e fitossanitários conforme recomendações para a cultura. O fornecimento de água foi efetuado por meio de sistema de irrigação por aspersão convencional.

Foram realizadas as seguintes avaliações na cultura da alface: altura de planta, diâmetro de caule, número de folhas por planta, matéria fresca de parte aérea, matéria seca de parte aérea e produtividade. Na cultura do repolho foram avaliados a área da planta (espaço ocupado pela planta), altura de planta, índice relativo de clorofila, número de folhas externas, número de folhas internas, altura da cabeça, diâmetro da cabeça e diâmetro do caule. Na cultura da salsa foram avaliadas no $1^{\circ}$ corte e na $1^{\mathrm{a}}$ e $2^{\mathrm{a}}$ rebrota a altura de planta, diâmetro de caule, matéria fresca de parte aérea, matéria seca de parte aérea e produtividade.

Os dados foram submetidos à análise de variância (teste F) e as médias comparadas pelo teste Tukey a 5\% de probabilidade. Para as doses de nitrogênio foram ajustadas análises de regressão. As análises estatísticas foram processadas com o aporte do programa de análise estatística Sanest.

\section{Resultados e Discussão \\ Desenvolvimento e produtividade de alface crespa}

Não foram observadas interações significativas em nenhuma das características estudadas na cultura da alface crespa Itapuã Super (Tabela 1). Para as avaliações altura de planta, diâmetro de caule, massa fresca de parte aérea, massa seca de parte aérea da alface em função das fontes de nitrogênio, não ocorreu efeito significativo (Tabela 1). Desta forma, o produtor pode utilizar uma fonte de $\mathrm{N}$ de menor custo sem afetar o desenvolvimento da planta e com reduzido custo de produção.

Para a produtividade da alface houve efeito significativo quando se utilizou a ureia revestida, sendo $21,4 \%$ maior àquela obtida em plantas adubadas com a ureia convencional. Essa diferença na produtividade está relacionada com a liberação lenta da ureia revestida, proporcionando às plantas maior aproveitamento do nutriente. De maneira geral, a produtividade obtida neste experimento é próxima à obtida por Araújo (2011) quando avaliou a produção da alface do tipo lisa cv. 'Verônica' em função da adubação nitrogenada. A maior produtividade da alface pode ser explicada devido ao uso do nitrogênio

Para as doses de nitrogênio observou-se resultado significativo apenas para o número de folhas (Tabela 1), cujos teores se ajustaram à regressão linear crescente (y $\left.=0,0220833 \mathrm{x}+17,650000, \mathrm{R}^{2}=0,92\right)$, em que os valores variaram de 17,75 a 23,62. Em alface, quanto maior o número de folhas maior será a matéria fresca resultando em produtividade; fator este de relevado interesse comercial.

Os resultados encontrados divergem dos obtidos por Araújo et al. (2011) onde os valores se ajustaram à regressão linear decrescente em função das doses de nitrogênio aplicadas, obtendo com o tratamento sem adição de $\mathrm{N}$ o valor máximo de 14,9 folhas por planta. Santos et al. (2011) obtiveram efeitos significativos da adubação nitrogenada para massa fresca, massa seca, altura e diâmetro de caule cujos dados se ajustaram à regressão quadrática com ponto máximo de 223; 225; 269 e $219 \mathrm{~kg} \mathrm{ha}^{-1}$ de N. Contudo, mesmo não ocorrendo 
efeito significativo, os valores obtidos neste trabalho para a massa fresca e altura de plantas foram superiores aos obtidos por Santos et al. (2011) quando alcançaram $107,9 \mathrm{~g}$ de massa fresca e altura média de plantas de $22,19 \mathrm{~cm}$; valores inferiores aos de Resende et al. (2005) que obtiveram a máxima produção de massa fresca comercial de 450,1 $\mathrm{g}_{\text {planta }}{ }^{-1}$.

$\mathrm{Na}$ literatura há grande divergência em relação aos resultados obtidos com a aplicação de nitrogênio na cultura da alface, sendo que os resultados podem ser influenciados pelo local, época de plantio, condições climáticas e o momento em que se realiza a adubação nitrogenada.

\section{Desenvolvimento e produtividade de repolho}

$\mathrm{Na}$ Tabela 2 estão os dados referentes às características de desenvolvimento do repolho híbrido Astrus Plus em função de fontes e doses de $\mathrm{N}$. Constatou-se que não houve efeito significativo da interação entre fontes e doses de $\mathrm{N}$ sobre as variáveis avaliadas (Tabela 2 e 3 ).
As variáveis área da planta, número de folhas externas, número de folhas internas, altura da cabeça, diâmetro da cabeça e diâmetro do caule na cultura do repolho não foram influenciadas pela aplicação das fontes de nitrogênio (Tabela 2).

Ressalta-se que, de acordo com estes resultados ambas as fontes de $\mathrm{N}$ podem ser utilizadas ficando a critério do produtor a opção que apresente menor custo aquisitivo. Resultados estes semelhantes aos de Ruiz Junior et al. (2012) que também não observaram efeito significativo de fontes de nitrogênio nas características agronômicas de crescimento e produtividade do repolho roxo. Porém, divergem dos resultados obtidos por Silva et al. (2012) que em comparação a este estudo alcançaram valores superiores de área, altura de plantas e número de folhas externas e valores inferiores quanto ao número de folhas internas e diâmetro de cabeça.

Para as doses de nitrogênio houve efeito significativo para as variáveis altura de planta $(\mathrm{y}=$ $\left.32,020000+0,004733 x, R^{2}=0,90\right)$ e altura da cabeça $(y$ $\left.=0,0047778+10,726667 \mathrm{x}, \mathrm{R}^{2}=0,70\right)$ onde os valores se ajustam a regressão linear positiva (Tabela 2).

Tabela 1. Altura de planta (ATL), diâmetro de caule (DIA), número de folhas (N FOL), massa fresca de parte aérea (MFA), massa seca de parte aérea (MSA) e produtividade (PROD) de alface em função da adubação nitrogenada em cobertura com ureia revestida e ureia convencional. Ipameri-GO, 2014.

\begin{tabular}{ccccccc}
\hline \multirow{2}{*}{ Fontes } & ALT & DIA & N FOL & MFA $(\mathrm{g})$ & MSA $(\mathrm{g})$ & PROD \\
\cline { 2 - 6 } & $(\mathrm{cm})$ & $(\mathrm{mm})$ & --- & $-----(\mathrm{g})$----- & $\left.(\mathrm{t} \mathrm{ha})^{-1}\right)$ \\
\hline Ureia revestida & $28,92 \mathrm{a}^{*}$ & $24,85 \mathrm{a}$ & $20,60 \mathrm{a}$ & $155,18 \mathrm{a}$ & $8,52 \mathrm{a}$ & $35,11 \mathrm{a}$ \\
Ureia convencional & $27,80 \mathrm{a}$ & $23,07 \mathrm{a}$ & $20,00 \mathrm{a}$ & $144,56 \mathrm{a}$ & $7,59 \mathrm{a}$ & $28,92 \mathrm{~b}$ \\
\hline Doses de N $\left(\mathrm{kg} \mathrm{ha}^{-1}\right)$ & & & & & \\
0 & $28,00^{\mathrm{NS}}$ & $22,98^{\mathrm{NS}}$ & $17,75^{(1)}$ & $146,90^{\mathrm{NS}}$ & $7,32^{\mathrm{NS}}$ & $34,86^{\mathrm{NS}}$ \\
60 & 26,93 & 21,41 & 19,25 & 140,26 & 7,60 & 29,63 \\
120 & 28,25 & 25,05 & 20,12 & 150,41 & 8,22 & 31,66 \\
180 & 29,75 & 26,78 & 20,75 & 152,01 & 9,74 & 31,98 \\
240 & 28,87 & 23,56 & 23,62 & 159,77 & 7,41 & 31,96 \\
\hline CV (\%) & 6,65 & 19,55 & 17,04 & 15,61 & 31,36 & 17,16 \\
\hline *Médias seguidas de mesma letra maíscula na coluna
\end{tabular}

*Médias seguidas de mesma letra maiúscula na coluna, para cada fator estudado, não diferem entre si pelo teste de Tukey a 5\% de probabilidade. ${ }^{2}$ não significativo. ${ }^{(1)} \mathrm{N}$ FOL: $\mathrm{y}=0,0220833 \mathrm{x}+17,650000 \mathrm{R}^{2}=0,92$.

Tabela 2. Valores médios da área da planta (ARPL), altura de planta (ALP), número de folhas externas (NFE), número de folhas internas (NFI), altura da cabeça (ALT CAB), diâmetro da cabeça (DIA CAB), diâmetro do caule (DIA CAU) de repolho em função da adubação nitrogenada em cobertura com ureia revestida e ureia convencional. Ipameri-GO, 2014.

\begin{tabular}{cccccccc}
\hline \multirow{2}{*}{ Fontes } & ARPL & ALP & NFE & NFI & ALT CAB & DIA CAB & DIA CAU \\
\cline { 2 - 7 } & $\left(\mathrm{m}^{2}\right)$ & $(\mathrm{cm})$ & ---- & ---- & $------(\mathrm{cm})$----- & $(\mathrm{mm})$ \\
\hline Ureia revestida & $0,20 \mathrm{a}^{*}$ & $33,00 \mathrm{a}$ & $11,72 \mathrm{a}$ & $38,12 \mathrm{a}$ & $11,23 \mathrm{a}$ & $15,52 \mathrm{a}$ & $19,26 \mathrm{a}$ \\
Ureia normal & $0,21 \mathrm{a}$ & $32,45 \mathrm{a}$ & $11,97 \mathrm{a}$ & $36,18 \mathrm{a}$ & $11,65 \mathrm{a}$ & $15,95 \mathrm{a}$ & $19,22 \mathrm{a}$ \\
\hline Doses de $\mathrm{N}\left(\mathrm{kg} \mathrm{ha}^{-1}\right)$ & & & & & & & \\
0 & $0,19^{\mathrm{NS}}$ & $32,70^{(1)}$ & $11,50^{\mathrm{NS}}$ & $37,10^{\mathrm{NS}}$ & $10,43^{(2)}$ & $15,43^{\mathrm{NS}}$ & $18,66^{\mathrm{NS}}$ \\
75 & 0,20 & 31,68 & 11,53 & 38,35 & 11,63 & 16,33 & 19,56 \\
150 & 0,21 & 31,10 & 11,98 & 36,43 & 11,15 & 15,98 & 18,28 \\
225 & 0,21 & 35,70 & 11,65 & 38,40 & 11,76 & 16,43 & 19,56 \\
300 & 0,22 & 32,46 & 12,56 & 35,46 & 12,18 & 14,51 & 20,13 \\
\hline CV $(\%)$ & 9,47 & 6,89 & 9,36 & 9,00 & 8,23 & 10,59 & 11,04 \\
\hline
\end{tabular}

*Médias seguidas de mesma letra na coluna, para cada fator estudado, não diferem entre si pelo teste de Tukey a 5\% de probabilidade. ${ }^{\text {NS }}$ não significativo. ${ }^{(1)}$ ALP: $y=32,020000+0,004733 x R^{2}=0,90 ;{ }^{(2)}$ ALT CAB: $y=0,0047778+10,726667 x R^{2}=0,70$. 
Tabela 3. Massa fresca de folhas externas (MFFE), massa seca de folhas externas (MSFE), massa fresca de folhas internas (MFFI), massa seca de folhas internas (MSFI), compacidade (COMP), índice relativo de clorofila (IRC) e produtividade (PROD) de repolho em função da adubação nitrogenada em cobertura com ureia revestida e ureia convencional. Ipameri-GO, 2014.

\begin{tabular}{llllllll}
\hline \multirow{2}{*}{ Fontes } & MFFE & MSFE & MFFI & MSFI & COMP & IRC & PROD \\
\cline { 2 - 7 } & $--------------(\mathrm{g})-------------$ & & & --- & $($ Spad $)$ & $\left.(\mathrm{t} \mathrm{ha})^{-1}\right)$ \\
\hline Ureia revestida & $145,60 \mathrm{a}^{*}$ & $22,59 \mathrm{a}$ & $106,52 \mathrm{a}$ & $9,40 \mathrm{~b}$ & $2,66 \mathrm{a}$ & $40,23 \mathrm{a}$ & $34,32 \mathrm{a}$ \\
Ureia convencional & $151,80 \mathrm{a}$ & $18,48 \mathrm{a}$ & $120,46 \mathrm{a}$ & $13,62 \mathrm{a}$ & $2,53 \mathrm{a}$ & $39,92 \mathrm{a}$ & $34,22 \mathrm{a}$ \\
\hline Doses de N $\left(\mathrm{kg} \mathrm{ha}^{-1}\right)$ & & & & & & & \\
0 & $135,66^{\mathrm{NS}}$ & $15,06^{\mathrm{NS}}$ & $101,33^{\mathrm{NS}}$ & $6,80^{(1)}$ & $2,36^{\mathrm{NS}}$ & $40,00^{\mathrm{NS}}$ & $36,44^{\mathrm{NS}}$ \\
75 & 154,50 & 18,96 & 120,15 & 9,15 & 2,68 & 38,73 & 36,66 \\
150 & 142,00 & 20,53 & 112,50 & 14,68 & 2,68 & 40,46 & 30,94 \\
225 & 157,66 & 23,07 & 120,66 & 15,93 & 2,65 & 40,26 & 35,91 \\
300 & 153,66 & 25,61 & 112,81 & 10,98 & 2,60 & 40,91 & 31,39 \\
\hline CV $(\%)$ & 15,72 & 35,68 & 16,79 & 28,61 & 9,19 & 5,36 & 21,38 \\
\hline
\end{tabular}

Médias seguidas de mesma letra na coluna, para cada fator estudado, não diferem entre si pelo teste de Tukey a $5 \%$ de probabilidade. ${ }^{\text {NS }}$ não significativo. ${ }^{(1)}$ MSFI: $y=-0,00023979 x^{2}+0,0921365 x+5,782381, R^{2}=0,83$

Para variável altura da planta mesmo diante de valores significativos observa-se que o seu aumento não influenciou diretamente nas características produtivas das plantas de repolho. Porém, a altura de cabeças é fator importante para a classificação comercial das cabeças de repolho.

Na Tabela 3 estão os valores da massa fresca de folhas externas, massa seca de folhas externas, massa fresca de folhas internas, massa seca de folhas internas, compacidade, índice relativo de clorofila e produtividade. Em relação aos efeitos de fontes de $\mathrm{N}$ constatou-se efeito significativo apenas a massa fresca das folhas internas com a utilização da ureia convencional. Para as demais avalições não houve efeito significativo para as fontes testadas (Tabela 3).

A massa seca de folhas internas foi influenciada significativamente pelas doses de nitrogênio cujos dados se ajustaram à uma regressão polinomial quadrática $(\mathrm{y}=$ $\left.-0,00023979 x^{2}+0,0921365 x+5,782381, R^{2}=0,83\right)$ com ponto de máximo estimado em 192,11 $\mathrm{kg} \mathrm{ha}^{-1}$ (Tabela 3). Este resultado demostra que as cabeças de repolho apresentaram boa formação. Mesmo não ocorrendo efeito significativo é importante ressaltar que a compacidade das cabeças apresentou variação entre de 2,36 a 2,60 para as doses 0 a $300 \quad \mathrm{~kg} \mathrm{ha}^{-1}$, respectivamente; resultados que corroboram aos de Moreira et al. (2011) quando também obtiveram ajuste quadrático para a massa seca de folhas de repolho em função de doses de nitrogênio.

\section{Desenvolvimento e produtividade de salsa}

No que se refere ao desenvolvimento e produtividade de salsa Graúda Portuguesa não foram detectadas interações significativas em nenhuma das características estudadas sobre o efeito da adubação de cobertura utilizando ureia normal e ureia revestida no cultivo da salsa (Tabela 4, 5 e 6).

Tabela 4. Altura de planta (ATL), diâmetro de caule (DIA), massa fresca de parte aérea (MFA), massa seca de parte aérea (MSA) e produtividade (PROD) de salsa em função da adubação nitrogenada em cobertura com ureia revestida e ureia convencional. IpameriGO, 2014.

\begin{tabular}{|c|c|c|c|c|c|}
\hline \multirow{2}{*}{ Fontes } & ALT & DIA & MFA & MSA & \multirow{2}{*}{$\begin{array}{l}\text { PROD } \\
\left(\mathrm{t} \mathrm{ha}^{-1}\right)\end{array}$} \\
\hline & $(\mathrm{cm})$ & $(\mathrm{mm})$ & \multicolumn{2}{|c|}{-------- (g) -------- } & \\
\hline Ureia revestida & $18,28 \mathrm{a}^{*}$ & $2,10 \mathrm{a}$ & $16,42 \mathrm{a}$ & 5,29 a & $3,18 \mathrm{a}$ \\
\hline Ureia convencional & $18,18 \mathrm{a}$ & $2,05 \mathrm{a}$ & $16,15 \mathrm{a}$ & $5,12 \mathrm{a}$ & $2,94 \mathrm{a}$ \\
\hline \multicolumn{6}{|l|}{ Doses de $\mathrm{N}\left(\mathrm{kg} \mathrm{ha}^{-1}\right)$} \\
\hline 0 & $16,40^{\mathrm{NS}}$ & $1,75^{\mathrm{NS}}$ & $13,82^{\mathrm{NS}}$ & $4,72^{\mathrm{NS}}$ & $2,94^{\mathrm{NS}}$ \\
\hline 40 & 17,68 & 1,93 & 16,08 & 5,12 & 2,70 \\
\hline 80 & 19,52 & 2,25 & 17,67 & 5,57 & 3,29 \\
\hline 120 & 19,42 & 2,27 & 16,38 & 5,39 & 3,61 \\
\hline 160 & 18,13 & 2,18 & 17,47 & 5,21 & 2,79 \\
\hline $\mathrm{CV}(\%)$ & 12,95 & 18,38 & 24,11 & 15,42 & 42,17 \\
\hline
\end{tabular}

*Médias seguidas de mesma letra maiúscula na coluna, para cada fator estudado, não diferem entre si pelo teste de Tukey a 5\% de probabilidade. NS não significativo. 
Tabela 5. Altura de planta (ALT), diâmetro de caule (DIA), massa fresca de parte aérea (MFA), massa seca de parte aérea (MSA) e produtividade (PROD) de salsa após primeira rebrota em função da adubação nitrogenada em cobertura com ureia revestida e ureia convencional. Ipameri-GO, 2014.

\begin{tabular}{|c|c|c|c|c|c|}
\hline \multirow{2}{*}{ Fontes } & ALT & DIA & MFA (g) & $\operatorname{MSA}(\mathrm{g})$ & \multirow{2}{*}{$\frac{\text { PROD }}{\left(\mathrm{t} \mathrm{ha}^{-1}\right)}$} \\
\hline & $(\mathrm{cm})$ & $(\mathrm{mm})$ & \multicolumn{2}{|c|}{------- (g) -------- } & \\
\hline Ureia revestida & $18,05 \mathrm{a}^{*}$ & $7,37 \mathrm{a}$ & $18,48 \mathrm{a}$ & $5,87 \mathrm{a}$ & $4,77 \mathrm{a}$ \\
\hline Ureia convencional & $18,54 \mathrm{a}$ & $7,97 \mathrm{a}$ & $16,16 \mathrm{a}$ & $5,32 \mathrm{~b}$ & $5,22 \mathrm{a}$ \\
\hline \multicolumn{6}{|l|}{ Doses de $\mathrm{N}\left(\mathrm{kg} \mathrm{ha}^{-1}\right)$} \\
\hline 0 & $15,02^{(1)}$ & $6,65^{(\mathrm{NS})}$ & $16,65^{(\mathrm{NS})}$ & $5,30^{(\mathrm{NS})}$ & $4,60^{(\mathrm{NS})}$ \\
\hline 40 & 17,76 & 7,62 & 19,46 & 5,88 & 3,97 \\
\hline 80 & 18,52 & 7,72 & 16,12 & 5,58 & 4,79 \\
\hline 120 & 20,80 & 8,58 & 17,05 & 5,46 & 5,93 \\
\hline 160 & 19,38 & 7,76 & 17,33 & 5,75 & 5,80 \\
\hline $\mathrm{CV}(\%)$ & 10,74 & 17,29 & 30,36 & 14,79 & 34,12 \\
\hline
\end{tabular}

*Médias seguidas de mesma letra maiúscula na coluna, para cada fator estudado, não diferem entre si pelo teste de Tukey a $5 \%$ de probabilidade. ${ }^{\text {NS }}$ não significativo. ${ }^{(1)} \mathrm{ALT}: \mathrm{y}=-0,00030301 \mathrm{x}^{2}+0,0778884 \mathrm{x}+14,977857, \mathrm{R}^{2}=0,92$.

Tabela 6. Altura de planta (ATL), diâmetro de caule (DIA), massa fresca de parte aérea (MFA), massa seca de parte aérea (MSA) e produtividade (PROD) de salsa após segunda rebrota em função da adubação nitrogenada em cobertura com ureia revestida e ureia convencional. Ipameri-GO, 2014.

\begin{tabular}{|c|c|c|c|c|c|}
\hline \multirow{2}{*}{ Fontes } & ALT & DIA & MFA & MSA & \multirow{2}{*}{$\begin{array}{l}\text { PROD } \\
\left(\mathrm{t} \mathrm{ha}^{-1}\right)\end{array}$} \\
\hline & $(\mathrm{cm})$ & $(\mathrm{mm})$ & \multicolumn{2}{|c|}{-------- (g) -------- } & \\
\hline Ureia revestida & $18,19 a^{*}$ & $7,66 \mathrm{a}$ & $27,57 \mathrm{a}$ & $7,99 \mathrm{a}$ & $6,97 \mathrm{a}$ \\
\hline Ureia convencional & $16,96 \mathrm{a}$ & $7,95 \mathrm{a}$ & $25,16 \mathrm{a}$ & $7,46 \mathrm{a}$ & $7,77 \mathrm{a}$ \\
\hline \multicolumn{6}{|l|}{ Doses de N $\left(\mathrm{kg} \mathrm{ha}^{-1}\right)$} \\
\hline 0 & $17,42^{(\mathrm{NS})}$ & $6,70^{(\mathrm{NS})}$ & $28,77^{(\mathrm{NS})}$ & $7,92^{(\mathrm{NS})}$ & $8,11^{(\mathrm{NS})}$ \\
\hline 40 & 16,47 & 7,58 & 22,81 & 7,16 & 5,83 \\
\hline 80 & 18,05 & 8,33 & 34,41 & 8,70 & 6,40 \\
\hline 120 & 17,82 & 8,26 & 23,85 & 7,65 & 8,13 \\
\hline 160 & 18,11 & 8,15 & 21,97 & 7,20 & 8,21 \\
\hline CV (\%) & 19,01 & 15,63 & 34,69 & 19,42 & 16,77 \\
\hline
\end{tabular}

*Médias seguidas de mesma letra maiúscula na coluna, para cada fator estudado, não diferem entre si pelo teste de Tukey a 5\% de probabilidade. ${ }^{N S}$ não significativo.

As doses de $\mathrm{N}$ influenciaram significativamente a altura de plantas na primeira rebrota da salsa com ajuste quadrático e ponto de mínimo estimado em $128,5 \mathrm{~kg} \mathrm{ha}^{-1}$ (Tabela 5). Nesta variável a aplicação nitrogenada influenciou diretamente no crescimento das plantas, sendo este resultado esperado pela ação que o nutriente exerce na planta.

Para os fatores de desenvolvimento e produtividade da salsa após segunda rebrota (terceira colheita) observa-se na Tabela 6 que as fontes de $\mathrm{N}$ utilizadas não influenciaram a altura de planta, diâmetro de caule, massa fresca de parte aérea, massa seca de parte aérea e produtividade. Também não foram observados efeitos significativos das doses sobre a altura de planta, diâmetro de caule, massa fresca de parte aérea, massa seca de parte aérea.

Ressalta-se a necessidade de maiores estudos a respeito da aplicação de fontes e doses nitrogenadas na cultura da salsa, sendo uma cultura de grande participação socioeconômica e folhosa cuja procura tem sido considerável pelo mercado consumidor para complemento de temperos e ornamentação de pratos mais requintados na culinária brasileira.

\section{Conclusões}

As fontes de nitrogênio não exercem influência nas características produtivas e de desenvolvimento das culturas de alface, repolho e salsa.

As doses de nitrogênio não influenciaram nas características produtivas da cultura da alface, repolho e salva.

\section{Agradecimentos}

À Universidade Estadual de Goiás (UEG), Campus Ipameri, pelo suporte na execução do projeto e pela bolsa produtividade PROBIP ao quinto autor e ao $\mathrm{CNPq}$ e PBIC/UEG pela bolsa de iniciação científica. 


\section{Referências Bibliográficas}

AQUINO, L. A.; PUIATTI, M.; PEREIRA, P. R. G.; PEREIRA, F. H. F.; CASTRO, M. R. S.; LADEIRA, I. R. Características produtivas do repolho em função de espaçamentos e doses de nitrogênio. Horticultura Brasileira, Brasília-DF, v.23, n.2, p.266-270, 2005.

ARAÚJO, W. F.; SOUSA, K. T. S.; VIANA, T. V. A.; AZEVEDO, B. M.; BARROS, M. M.; MARCOLINO, E. Resposta da alface a adubação nitrogenada. Revista Agro@mbiente On-line, Boa Vista-RR, v. 5, n. 1, p. 12-17, 2011.

BENINNI, E. R. Y.; TAKAHASHI, H. W.; NEVES, C. S. V. Concentração e acúmulo de macronutrientes em alface cultivada em sistemas hidropônico e convencional. Semina: Ciências Agrárias, Londrina-PR, v. 26, n. 3, p. 273-282, 2005.

CAETANO, A. O.; DINIZ, R. L. C.; BENETT, C. G. S.; SALOMÃO, L. C. Efeito de fontes e doses de nitrogênio na cultura do rabanete. Revista de Agricultura Neotropical, Cassilândia-MS, v. 2, n. 4, p. 55-59, 2015.

CARVALHO, N. M.; NAKAGAWA, J. Sementes: Ciência, Tecnologia e Produção. Jaboticabal-SP: FUNEP, 2000. 588p.

DIN, M.; QASIM, M.; ALAM, M. Effect of different levels of $\mathrm{N}, \mathrm{P}$ and $\mathrm{K}$ on the growth and yield of cabbage. Journal of Agriculture Research, Lahore, Pakistanv, v. 45, n. 2, p. 171176, 2012.

EMBRAPA. EMPRESA BRASILEIRA DE PESQUISA AGROPECUÁRIA. Centro Nacional de Pesquisa de Solos. Sistema brasileiro de classificação de solos. Brasília-DF: Empresa Brasileira de Pesquisa Agropecuária, 2006. 305p.

EPSTEIN, E.; BLOOM, A. J. Mineral nutrition of plants: principçes and persperctive. 2 ed. Sunderland: Sinauer Associates, 2005. 400p.

FILGUEIRA F. A. R. Novo Manual de Olericultura: Agrotecnologia moderna na produção e comercialização de hortaliças. 3 ed. Viçosa-MG: Editora UFV, 2012. 421p.

FURLANI, P. R.; PURQUERIO, L. F. V. Avanços e desafios na nutrição de hortaliças. In: PRADO, R. M.; CECILIO FILHO, A. B.; CORREIA, M. A. R.; PUGA, A. P. Nutrição de Plantas: diagnose foliar em hortaliças. Jaboticabal-SP: FCAV/CAPES/FUNDUNESP, 2010, p.45-62.

HAQUE, K. M. F.; JAHANGIR, A. A.; HAQUE, M. E.; MONDAL, R. K.; JAHAN, M. A. A.; SARKER, M. A. M. Yield and nutritional quality of cabbages as affected by nitrogen and phosphorus fertilization. Bangladesh Journal of Scientific and Industrial Research, Bangladesh, v. 41, n. 1/2, p. 41-46, 2006.

HEREDIA Z., N. A.; VIEIRA, M. C.; WEISMANN, M.; LOURENÇÃO, A. L. F. Produção e renda bruta de cebolinha e de salsa em cultivo solteiro e consorciado. Horticultura Brasileira, Brasília-DF, v. 21, n. 3, p. 574-577, 2003.
LEZANA JÚNIOR; CARRASCO I. 3,4-dimetilpirazol fosfato (dmpp): el nuevo inhibidor de la nitrificación para fertilizantes - Experiências en sistemas de fertirrigación. Vida Rural, Lisboa, v. 22, p. 49-50, 2002.

MOREIRA, M. A.; VIDIGAL, S. M.; SEDIYAMA, M. A. N.; SANTOS, M.R. Crescimento e produção de repolho em função de doses de nitrogênio. Horticultura Brasileira, Brasília-DF, v. 29, n. 1, p. 117-121, 2011

MOREIRA, M. A.; VIDIGAL, S. M. Evolução das características da planta associadas à nutrição nitrogenada de repolho. Revista Ceres, Viçosa-MG, v. 58, n.2, p. 243-248, 2011.

PEREIRA, O. C. N.; BERTONHA, A.; FREITAS, P. S. L.; GONÇALVES, A. C. A.; REZENDE, R.; SILVA, F. F. Produção de alface em função de água e de nitrogênio. Acta Scientiarum Agronomy, Maringá-PR, v. 25, n. 2, p. 381-386, 2003.

RESENDE, G. M.; ALVARENGA, M. A. R.; YURI, J. E.; MOTA, J. H.; SOUZA, R. J.; RODRIGUES JÙNIOR, J. C. Produtividade e qualidade pós-colheita da alface americana em função de doses de nitrogênio e molibdênio. Horticultura Brasileira, Brasília-DF, v. 23, n. 4, p. 976-981, 2005.

RIBEIRO, A. C.; GUIMARÃES, P. T. G.; ALVAREZ, V. H. Recomendações para o uso de corretivos e fertilizantes em Minas Gerais - $5^{\text {a }}$ aproximação. Viçosa-MG: UFV, 1999. 359p.

RUIZ JUNIOR, E. C.; GONÇALVES, F. M.; MICHELAN, K. S.; HORA, R. C. Avaliação fitotécnica de plantas de repolho roxo cultivadas sob diferentes densidades e fontes de nitrogênio. Cultivando o Saber, Cascavel-PR, v. 5, n. 4, p. 124-132, 2012.

SANTOS, H. G.; JACOMINE, P. K. T.; ANJOS, L. H. C.; OLIVEIRA, V. A.; LUMBRERAS, J. F.; COELHO, M. R.; ALMEIDA, J. A.; CUNHA, T. J. F.; OLIVEIRA, J. B. Sistema brasileiro de classificação de solos. 3. ed. BrasíliaDF: Embrapa, 2013. 353p.

SANTOS, R. F.; BORSOI, A.; TOMAZZONI, J. L.; VIANA, O. H.; MAGGI, M. F. Aplicação de nitrogênio na cultura da alface. Revista Varia Scientia Agrárias, Cascavel-PR v. 2, n. 2, p. 63-74, 2011.

SILVA, A. A.; SILVA, T. S.; VASCONCELOS, A. C. P.; LANA, R. M. Q. Aplicação de diferentes fontes de ureia de liberação gradual na cultura do milho. Bioscience Journal, Uberlândia-MG, v. 28, n. 1, p. 104-111, 2012.

ZAGO, V. C. P.; EVANGELISTA, M. R.; ALMEIDA, D. L.; GUERRA, J. G. M.; RUMJANEK, N. G.; NEVES, M. C. P. Influência de diferentes fontes e doses de adubos nitrogenados nos teores de n-nitrato e na produtividade de alface. Scientia Agraria Paranaensis, Marechal Cândido Rondon-PR, v. 7, n. 1, p. 15-24, 2008 